\title{
REPRODUCTIVE ISOLATION AS A PLEIOTROPIC EFFECT OF COPPER TOLERANCE IN MIMULUS GUTTATUS?
}

\author{
M. R. MACNAIR AND P. CHRISTIE \\ Department of Biological Sciences, University of Exeter, Exeter, Devon, EX4 4QG, U.K.
}

Received 11.x.82

\section{SUMMARY}

\begin{abstract}
A genetic system producing postmating reproductive isolation between two populations of Mimulus guttatus is described. In one population, Copperopolis, there is a single gene tightly linked to, or pleiotropic to, the gene for copper tolerance. In the other, Cerig-y-drudion, a limited number of genes are involved. The genes interact in a complementary manner to produce F1 inviability. These results suggest that reproductive isolation could evolve as a direct result of adaptive differentiation in sympatry.
\end{abstract}

\section{INTRODUCTION}

The existence of barriers to reproduction is one of the ways in which species are frequently distinguished and their development is intimately associated with the process of speciation. The genetical basis of such barriers is therefore of great importance to an understanding of speciation and species differentiation. Mating barriers can be of many different types, but particularly important is the distinction between prezygotic mechanisms, in which gamete fusion is prevented, and postzygotic barriers, in which the fitness of the hybrid is reduced in some way in the F1 or later generations (see Levin, 1978). Many have suggested that it is possible for prezygotic barriers between two populations to evolve as a direct result of selection for reduced hybrid formation (the so-called "Wallace effect"). Evidence that this process may operate comes from a number of sources (e.g., Paterniani, 1969; Thoday and Gibson, 1962; McNeilly and Antonovics, 1968) but its importance in nature is not yet certain. Postzygotic barriers on the other hand cannot normally be selected for (but see Coyne, 1974) and are believed to arise in allopatric populations as a by-product of differentiation. The present paper is concerned with the genetic basis of a postmating barrier in which the F1 hybrid is inviable. In principle, hybrid inviability can be produced by a genetic system in which a gene or genes interact in one of two ways: (a) heterozygote disadvantage i.e., AA or aa are viable, but $\mathrm{Aa}$ is not or (b) complementary epistasis i.e., AAbb or aaBB are viable but $\mathrm{AaBb}$ is not. Any genetic system of either of these types, in which the different elements of the interacting system are found in separate species or populations, can be regarded as a crossing barrier. In only a few cases is anything known about the number of genes involved in a particular system isolating species. Traditionally (e.g., Mayr, 1970) it is believed that a very large number of genes are involved. Some studies have tended to confirm this view, for instance in Drosophila (e.g., Dobzhansky, 1936; Carson, 1978; Patterson and Stone, 1952) and Podisma 
pedestris (Barton and Hewitt, 1981). Other workers however have found instances where only one or a few pairs of genes seem to be involved. Many of these cases of simple genetic control involve plant species, particularly cultivated plants (see Levin, 1978), but examples in animals include Drosophila pseudoobscura (Prakash, 1972) and Partula suturalis (Clarke and Murray, 1969 and Pers. Comm.).

The yellow monkey flower, Mimulus guttatus, has also developed partial postmating isolation between some races. Vickery has been studying $M$. guttatus and its related species over many years (see Vickery 1979 for a review). He has found that though the barriers isolating species tend to be stronger than those isolating populations within a species, these barriers are not generally qualitatively different. In this paper we investigate the genetics of one system partially isolating two populations, Copperopolis and Cerig, and show that the gene in Copperopolis is the same as, or possibly tightly linked to, a gene giving copper tolerance.

\section{MATERIALS AND METHODS}

The materials and methods are essentially those described in the accompanying paper (Macnair, 1983). Only a brief summary of the main features of the parent plants, and cultivation and tolerance testing methods will be given here.

\section{(i) Provenance of the parents}

The crosses reported here are derived from individuals from the following populations:

(a) Copperopolis: A copper tolerant population described by Allen and Sheppard (1971). A single plant (C10) was used from this population.

(b) British non-tolerant populations: Plants were taken from two populations: Cerig-y-drudion (abbreviated to Cerig or Cer) and Wardle. Details of Cerig will also be found in Allen and Sheppard (1971); the Wardle population was collected from the banks of the Shropshire Union Canal, grid reference SJ607 575. Many of the crosses described here involve a particular Cerig plant, Cer 34.

\section{(ii) Cultivation}

Except for a few of the very early families, all families were grown in seed trays. Unless otherwise stated, families were grown in JI compost in $35 \mathrm{~mm} \times 23 \mathrm{~cm}$ seed trays.

\section{(iii) Tolerance testing}

Individuals were tested for copper tolerance on the basis of whether or not they formed proper roots in a solution of $0.5 \mathrm{ppm} \mathrm{Cu}$ in $0.5 \mathrm{gl}^{-1}$ calcium nitrate. 


\section{Results}

(i) The identification and characterization of the phenomenon

When Copperopolis and Cerig plants were first crossed a partial crossing barrier, involving the deaths of some F1 plants, was detected. This barrier reappeared in the first backcross $(F 1 \times$ Cerig). Plants affected by the barrier grow normally until at least the 4 leaf stage. At this point, or later, the leaves begin to yellow and become progressively necrotic. Further growth is inhibited. Plants affected early nearly always die rapidly; plants affected later may survive for considerable periods. In the absence of competition from other plants some continue to grow very slowly for many months. Some sideshoots are produced but older leaves on both sideshoots and the main axis continue to die.

The crossing barrier only appeared in crosses between tolerant ( $\mathrm{T})$ and non-tolerant (NT) plants. It is observed in various sets of crosses involving the descendants of the original $\mathrm{C} 10 \times \mathrm{Cer} 34$ cross. These crosses were:

\section{(a) Backcrosses to British plants}

All backcrosses of tolerant plants to Cerig or Wardle plants show the crossing barrier. In addition to the first backcross, four tolerant members of this backcross (plants 5556/54, 5556/57, 5556/62, 5556/64) were backcrossed to Cerig plants, and two were backcrossed to a Wardle plant (backcross 2). One plant from the selfed progeny of 5556/57 was also crossed to a Wardle plant (Backcross 3). All families were scored for $\mathrm{T}: \mathrm{NT}:$ Dead ratio. The results are given in table 1 .

TABLE 1

Summary of the eighteen $T \times N T$ families showing the crossing barrier

\begin{tabular}{lrrr}
\hline & T & NT & Dead \\
\hline Backcross 1 (1 family) & 4 & 9 & 8 \\
Backcross 2 (6 families) & 43 & 92 & 57 \\
BC intercross 1 (8 families) & 111 & 225 & 186 \\
Backcross 3 (1 family) & 15 & 32 & 10 \\
BC intercross 2 (2 families) & 22 & 57 & 36 \\
& 195 & 415 & 297 \\
Heterogeneity $\chi^{2}$ of all 18 families: & \\
Total (34 df) $=36 \cdot 13 \mathrm{NS} ;$ \\
T vs. NT (17 df)=10.72 NS; \\
(T+NT) vs. dead (17 df)=25.62 NS. \\
\hline
\end{tabular}

\section{(b) Intercrosses amongst backcross 1 plants and their progeny}

The four tolerant plants from the first backcross were crossed to three of their non-tolerant sibs (plants 5556/56, 5556/69 and 5556/74). The 12 families give significant heterogeneity for $\mathrm{T}: \mathrm{NT}$ : Dead ratio, which can be shown to be associated with the particular NT parent used. Table 2(a) shows the $4 \times 3$ table obtained if the families are pooled by tolerant parent; the four tolerants are not heterogeneous, but each set of 3 families within 
TABLE 2

Pooled data from the 12 families produced by crossing the four tolerant plants 5556/54, 5556/57, 5556/62, 5556/64 with their three nontolerant sibs, 5556/56, 5556/69, and 5556/74

\begin{tabular}{ccccc}
\hline \multicolumn{5}{c}{ (a) Pooled by tolerant parent } \\
\hline Parent & T & NT & Dead & Heterogeneity $\chi_{4}^{2}$ \\
\hline 54 & 59 & 87 & 55 & $39 \cdot 3^{* * *}$ \\
57 & 50 & 98 & 53 & $26 \cdot 5^{* * *}$ \\
62 & 69 & 91 & 41 & $32 \cdot 6^{* * *}$ \\
64 & 45 & 89 & 49 & $145^{* * *}$ \\
& \multicolumn{5}{c}{ Overall $\chi_{6}^{2}=7 \cdot 8 \mathrm{NS}$} \\
\hline
\end{tabular}

(b) Pooled by non-tolerant parent

\begin{tabular}{crccc}
\hline Parent & T & NT & Dead & Heterogeneity $\chi_{6}^{2}$ \\
\hline 56 & 55 & 112 & 94 & $5 \cdot 2$ \\
69 & 56 & 113 & 92 & $10 \cdot 2$ \\
74 & 112 & 140 & 12 & $6 \cdot 62$ \\
& & Overall $\chi_{4}^{2}=98 \cdot 7^{* * *}$ & \\
\hline
\end{tabular}

Note: Heterogeneity $\chi^{2}$ is the heterogeneity between families sharing that parent; the overall $\chi^{2}$ is the contingency $\chi^{2}$ for the pooled table.

*** $p<0.001$.

each tolerant parent is. In table 2(b) the data are pooled by NT parent; now the within parent heterogeneity is non-significant in each case, but the between parent heterogeneity is enormous. It is obvious that this is caused by the families with $5556 / 56$ or $5556 / 69$ as a parent having a much higher death rate than those with $5556 / 74$; these eight families also have a much lower $\mathrm{T}: \mathrm{NT}$ ratio. The pooled data from these eight families are also included in table 1 (BC intercross 1 ).

The phenomenon was also noted in intercrosses between progeny of the crosses between 5556 plants. Of $17 \mathrm{~T} \times \mathrm{NT}$ crosses involving such plants, 2 showed the crossing barrier. The data from these two families are also included in table 1 (BC intercross 2). From table 1 it is clear that all 18 families show both a high death rate and a low $\mathrm{T}: \mathrm{NT}$ ratio. In the accompanying paper (Macnair, 1983) it is shown that copper tolerance is governed by a single major gene, and that segregating $\mathrm{T} \times \mathrm{NT}$ crosses with a normal death rate give approximately $1 \mathrm{~T}: 1 \mathrm{NT}$ ratio. Thus it appears that tolerant individuals are dying more frequently than non-tolerants, indicating genetic linkage between this phenomenon and the tolerance gene.

If the $\mathrm{T}: \mathrm{NT}$ ratio should be $1: 1$, it is evident from table 1 that approximately half of the tolerants must have died. The simplest genetic model giving such a result is as follows. The original tolerant parent $(\mathrm{C10})$ was homozygous for the tolerance gene $(\mathrm{T})$ which is linked to another gene (Sl) which produces a synthetic lethal when in combination with another unlinked gene, A. C10 was therefore $\mathrm{T}^{\mathrm{Sl}} \mathrm{T}^{\mathrm{sl}}$ aa. Cer 34 is $\mathrm{tt}$, and must be heterozygous for $A$ since not all the F1 die. The F1 will therefore be of two types, $\mathrm{T}^{\mathrm{Sl}}$ tAa (which die) and $\mathrm{T}^{\mathrm{Sl}}$ taa. The backcross to Cerig produces $\frac{1}{4}$ dead, $\frac{1}{4} \mathrm{~T}$, and $\frac{1}{2} \mathrm{NT}$, with these being of two types, ttAa which will behave 
like Cer 34 when crossed to their tolerant sibs, and ttaa which will not. The problem with this simple model is that it predicts that all Cerig plants used in these crosses must be heterozygous like Cer 34. Six different Cerig and Wardle parents were used-with a one gene model it is unlikely that all six would be heterozygous.

\section{(ii) Testing the model}

This model predicts that the selfed progeny of Cer 34 should segregate, and produce offspring that vary in the ratio of deaths they produce when crossed to plants containing Sl. the selfed progeny of $\mathrm{C} 10$ should, however, not be so variable. Accordingly, 10 progeny of Cer 34 were crossed in all possible ways with 10 progeny of $\mathrm{C} 10$. To check that there were no genes other than $\mathrm{T}^{\mathrm{SI}}$ in $\mathrm{C} 10$ that would cause death with $\mathrm{Cer} 34$, a number of the Cer 34 progeny were also crossed to a plant heterozygous for the tolerance gene with only an eighth of its genome derived from Copperopolis. The proportion of affected plants in these crosses was approximately half those in the crosses to $\mathrm{C} 10$ progeny, thus confirming that the $\mathrm{T}^{\mathrm{Si}}$ gene was the principal factor causing the synthetic lethal reaction in $\mathrm{C} 10$. These crosses also confirmed the association between the tolerance gene and the synthetic lethal reaction.

Because of space limitations it was not possible to grow all 100 crosses involved in this experiment at once. Thus the crosses were grown in two batches: in the first the crosses involving 4 of the Cer 34 progeny were grown, the crosses with the other six being in the second batch. The four plants in the first set were deliberately chosen to represent different classes of ratio that had appeared to be present from the crosses to the heterozygote. Each family was represented by two half size seed trays containing 30 individuals each, and each set was fully randomised.

The number of individuals showing the crossing barrier in each tray was scored periodically. The proportions affected (expressed as proportions of totals in tray, excluding any that died from natural causes) were arcsin transformed and analysed by a two way ANOVA. The results for the two sets are given in table 3 . Set 1 was destroyed relatively earlier than set 2 , and only the analysis of the final proportions is given. The analysis for set 2 is given after 8 weeks, 10 weeks and 12 weeks. In both sets, there are obvious differences between the ratios produced by Cer 34 progeny, thus confirming that Cer 34 was heterozygous, and is producing variable progeny. There were also slight differences between $\mathrm{C} 10$ progeny, indicating that $\mathrm{C} 10$ was not homozygous for all relevant loci. However, there is evidence from set 2 that the difference between the $\mathrm{C} 10$ progeny relates to the rate of onset of the incompatibility reaction since the magnitude of the $\mathrm{C} 10$ progeny item decreases between weeks 10 and 12 . The marginal totals for Cer 34 progeny are given in table 4 . In set 1 , each of the Cer 34 progeny is different to the others; in set 2 there also appear to be at least 4 classes of ratio produced. Combining the two sets, there must be at least 5 and possibly 6 different classes of ratio. The number of classes of progeny amongst the progeny of Cer 34 implies that there must be at least two and probably more genes controlling the Cerig side of this mating barrier: however the spread of ratios produced in a progeny of 10 (100 per cent deaths to about 8 per cent) also suggests that there cannot be very many. 
TABLE 3

ANOVA of proportions (arcsine transformed) of affected seedlings in families from the C10X Cer 34 series of crosses

(a) Set 1

\begin{tabular}{lrrc}
\hline \multicolumn{1}{c}{ Item } & df & MS & F \\
\hline Cer 34 self & 1 & 377 & $27 \cdot 7^{* * *}$ \\
C10 self & 9 & 60 & $4 \cdot 4^{* * *}$ \\
Cer 34 $\times$ C10 & 9 & 42 & $3 \cdot 1^{*}$ \\
error & 20 & 14 & \\
\hline
\end{tabular}

Note: Only the two Cer 34 parents giving intermediate death rates have been included in this analysis.

(b) Set 2

\begin{tabular}{|c|c|c|c|c|c|c|c|}
\hline \multirow[b]{2}{*}{ Item } & \multirow[b]{2}{*}{ df } & \multicolumn{2}{|c|}{8 weeks } & \multicolumn{2}{|c|}{10 weeks } & \multicolumn{2}{|c|}{12 weeks } \\
\hline & & MS & F & MS & F & MS & $\mathrm{F}$ \\
\hline Cer 34 self & 5 & 2226 & $50 \cdot 6^{* * *}$ & 2083 & $44 \cdot 3^{* * *}$ & 1619 & $36 \cdot 6^{* * *}$ \\
\hline C10 self & 9 & 129 & $2 \cdot 9^{*}$ & 136 & $2 \cdot 9^{*}$ & 68 & $1.5 \mathrm{NS}$ \\
\hline Cer $34 \times \mathrm{C} 10$ & 45 & 70 & $1.6 \mathrm{NS}$ & 53 & $1 \cdot 1 \mathrm{NS}$ & 54 & $1.2 \mathrm{NS}$ \\
\hline error & 60 & 44 & & 47 & & 44 & \\
\hline
\end{tabular}

${ }^{* * *} p<0.001,{ }^{* *} p<0.01, * p<0.05$.

TABLE 4

Percentage dead or dying seedlings from crosses between Cer 34 and C10 progenies. Numbers have been summed over C10 progeny. In set 2, plants dying immediately after pricking out and a few selfs have been excluded from the totals. The four percentages in set 1 are significantly different from each other; the bars underneath set 2 indicate values that are not significantly different at the 0.05 level

\begin{tabular}{|c|c|c|c|c|c|c|c|c|c|c|}
\hline \multirow[b]{2}{*}{ Cer 34 self } & \multicolumn{4}{|c|}{ SET 1} & \multicolumn{6}{|c|}{ SET 2} \\
\hline & 3 & 1 & 10 & 6 & 8 & 7 & 2 & 5 & 4 & 9 \\
\hline $\mathbf{N}$ & 600 & 600 & 600 & 600 & 569 & 580 & 563 & 587 & 570 & 573 \\
\hline $\begin{array}{l}\text { Percentage } \\
\text { dead or } \\
\text { dying }\end{array}$ & 100 & $46 \cdot 5$ & $36 \cdot 3$ & $7 \cdot 8$ & $43 \cdot 3$ & $30 \cdot 0$ & $21 \cdot 6$ & $19 \cdot 5$ & $16 \cdot 2$ & $12 \cdot 4$ \\
\hline
\end{tabular}

Further research is required before the number of genes and the way they interact can be determined more accurately in Cerig; it is clear, however, that the reaction in Copperopolis is controlled principally by one gene linked to the copper tolerance gene, though there may be other genes affecting the time of onset and penetrance of the reaction.

\section{(iii) The tightness of the linkage between $T$ and $S l$}

The genes $\mathrm{T}$ and $\mathrm{Sl}$ in Copperopolis are evidently tightly linked, though the exact degree of linkage is still unclear. Out of several hundred plants that have been scored in which recombination could have been detected, only a single possible recombinant has been found. It is possible that this plant was a contaminant or that it survived due to the variable penetrance 
of this reaction, seen particularly in some of the crosses to $\mathrm{C} 10$ progeny. The data are compatible with the synthetic lethal reaction being a pleiotropic effect of the tolerance gene. Certainly it is difficult to believe that the association of the two phenomena is purely fortuitous. $M$. guttatus has a diploid chromosome number of $2 n=28$, so two genes taken at random are unlikely to be very tightly linked.

\section{Discussion}

Two conclusions emerge from the data reported here. First, total postzygotic reproductive isolation between two populations, in the sense that inviable zygotes are formed, can be produced by a comparatively simple genetic mechanism. Here a single gene in one population interacts with a small number in the other. Secondly the gene which is responsible for one half of the crossing barrier is possibly the same gene which gives an adaptive response to a known environmental variable.

Many have argued (e.g., Mayr, 1970) that the genetic differences causing reproductive isolation between species must involve many genes and be the by-product of the differentiation of the genomes of two populations at hundreds, perhaps thousands, of loci. If this is true, it is clear that speciation will only be possible when gene flow between two differentiating populations is negligible. For if many hundreds of interacting gene systems must be changed before isolation can be achieved, then the selection acting on any one system must be small, and be easily opposed by the cohesion imposed by gene flow from other populations.

However, in many natural circumstances the selective value of a single gene is high enough to result in its spread through part of a population despite gene flow. The gene conferring copper tolerance in $M$. guttatus is a case in point. Clearly, if such an adaptive gene produces reproductive isolation as a pleiotropic effect, as may well be the case here, then reproductive isolation and speciation may be initiated very easily, even in the face of considerable gene flow.

A number of other examples of reproductive isolation with a simple genetic basis are known, particularly in plants. Single pairs of complementary genes have been shown to produce postzygotic isolation in rice (Chu and Oka, 1972, Oka, 1974), wheat (Hermesen, 1963), cotton (Stephens, 1950; Gerstel, 1954), barley (Weibe, 1934), sweet clover (Sano and Kita, 1978), cowpeas (Saunders, 1952), Crepis (Hollingshead, 1930) and Hutchinsa (Melchers, 1939). In none of these instances, however, is there any evidence that any of the genes involved is of any adaptive significance. It is clear however, that in plants anyway, reproductive isolation can be achieved simply, and could swiftly follow an adaptive response.

Acknowledgements. Part of this work was supported by a NERC grant GR3/4254. We thank Dr P. M. Brakefield and an anonymous referee for many helpful comments on an earlier draft of this paper.

\section{REFERENCES}

ALLEN, W. R. AND SHEPPARD, P. M. 1971. Copper tolerance in some Californian populations of the monkey flower, Mimulus guttatus. Proc. R. Soc. B., 177, 177-196. 
BARTON, N. H. AND HEWITT, G. M. 1981. The genetic basis of hybrid inviability in the grasshopper Podisma pedestris. Heredity, 47, 367-383.

CARSON, H. L. 1978. Speciation and sexual selection in Hawaiian Drosophila. In Brussard, P. F. (ed.) Ecological Genetics: the interface, Springer-Verlag, pp. 93-107.

CHU, Y. E. AND OKA, H. I. 1972. The distribution and effects of genes causing F1 weakness in Oryza breviligulata and $O$. glaberrima. Genetics, 70, 163-173.

CLARKE, B. C. AND MURRAY, J. J. 1969. Ecology, genetics, and speciation in land snails of the genus Partula. Biol. J. Linn. Soc. London 1, 31-42.

COYNE, J. A. 1974. The evolutionary origin of hybrid inviability. Evolution, 28, 505-506.

DOBZHANSKY, T. 1936. Studies on hybrid sterility. II. Localization of sterility factors in Drosophila pseudoobscura hybrids. Genetics, 21, 113-135.

GERSTEL, D. U. 1954. A new lethal combination in interspecific cotton hybrids. Genetics, $39,628-639$.

HERMESEN, J. G. T. 1963. The genetic basis of hybrid necrosis in wheat. Genetica, 33, 245-287.

HOLLINGSHEAD, L. 1930. A lethal factor in Crepis effective only in an interspecific hybrid. Genetics, 15, 114-140.

LEVIN, D. A. 1978. The origin of isolating mechanisms in flowering plants. Evol. Biol. 11, 185-317.

MACNAIR, M. R. 1983. The genetic control of Copper Tolerance in the Yellow Monkey flower, Mimulus guttatus. Heredity, 50, 283-293.

McNEILLY, T. AND ANTONOVICS, J. 1968. Evolution in closely adjacent plant populations. IV. Barriers to gene flow. Heredity, 23, 205-218.

MAYR, E. 1970. Populations, Species and Evolution. Harvard Univ. Press, Cambridge, Mass. MELCHERS, G. 1939. Genetik und Evolution. Z. i. A.V., 76, 229-259.

OKA, H. I. 1974. Analysis of genes controlling F1 sterility in rice by the use of isogenic lines. Genetics, 77, 521-534.

PATERNIANI, E. 1969. Selection for reproductive isolation between two populations of maize, Zea mays L., Evolution, 23, 534-547.

PATtERSON, J. T. AND StONE, W. S. 1952. Evolution in the Genus Drosophila. Macmillan, New York.

PRAKASH, S. 1972. Origin of reproductive isolation in the absence of apparent genic differentiation in a geographic isolate of Drosophila pseudoobscura. Genetics, 72, 143-155.

SANO, Y, AND KITA, F. 1978. Reproductive barriers distributed in Melilotus species and their genetic bases. Can. J. Genet. Cytol. 20, 275-289.

SAUNDERS, A. P. 1952. Complementary lethal genes in the cowpea. S. African J. Sci., 48, 195-197.

STEPHENS, S. G. 1950. The genetics of "corky". II. Further studies on its genetic basis in relation to the general problem of interspecific isolating mechanisms. J. Genet., 50, 9-20.

THODAY, J. M. AND GIBSON, J. B. 1962. Isolation by disruptive selection. Nature, 193, 1164-1166.

VICKERY, R, K. 1979. Case studies in the evolution of species complexes in Mimulus. Evol. Biol., 11, 405-507.

WIEBE, G. A. 1934. Complementary factors in barley giving a lethal progeny. J. Hered. 25, 273-274. 